\title{
The irrelevant speech effect: a PET study ${ }^{\text {is }}$
}

\author{
Jens Gisselgård $^{\mathrm{a}}$, Karl Magnus Petersson ${ }^{\mathrm{a}, \mathrm{b}, \mathrm{c}, *}$, Alan Baddeley ${ }^{\mathrm{d}}$, Martin Ingvar ${ }^{\mathrm{a}}$

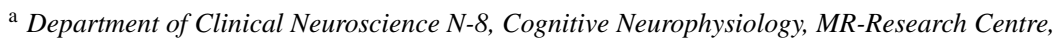 \\ Karolinska Institute, Karolinska Hospital, 17176 Stockholm, Sweden \\ ${ }^{\mathrm{b}}$ Neurocognition of Language Research Group, Max Planck Institute for Psycholinguistics, P.O. Box 310, NL-6500 AH Nijmegen, The Netherlands \\ ${ }^{\mathrm{c}}$ F.C. Donders Centre for Cognitive Neuroimaging, Katholieke Universiteit Nijmegen, Nijmegen, The Netherlands \\ ${ }^{\mathrm{d}}$ Department of Experimental Psychology, University of Bristol, 8 Woodland Road, Bristol BS8 1TN, UK
}

Received 21 November 2002; received in revised form 21 May 2003; accepted 22 May 2003

\begin{abstract}
Positron emission tomography (PET) was performed in normal volunteers during a serial recall task under the influence of irrelevant speech comprising both single item repetition and multi-item sequences. An interaction approach was used to identify brain areas specifically related to the irrelevant speech effect. We interpreted activations as compensatory recruitment of complementary working memory processing, and decreased activity in terms of suppression of task relevant areas invoked by the irrelevant speech. The interaction between the distractors and working memory revealed a significant effect in the left, and to a lesser extent in the right, superior temporal region, indicating that initial phonological processing was relatively suppressed. Additional areas of decreased activity were observed in an a priori defined cortical network related to verbal working memory, incorporating the bilateral superior temporal and inferior/middle frontal cortices extending into Broca's area on the left. We also observed a weak activation in the left inferior parietal cortex, a region suggested to reflect the phonological store, the subcomponent where the interference is assumed to take place. The results suggest that the irrelevant speech effect is correlated with and thus tentatively may be explained in terms of a suppression of components of the verbal working memory network as outlined. The results can be interpreted in terms of inhibitory top-down attentional mechanisms attenuating the influence of the irrelevant speech, although additional studies are clearly necessary to more fully characterize the nature of this phenomenon and its theoretical implications for existing short-term memory models.
\end{abstract}

(c) 2003 Elsevier Ltd. All rights reserved.

Keywords: Working memory; Short-term memory; Attentional modulation; Functional imaging

\section{Introduction}

The irrelevant speech effect refers to a reduction in the immediate serial recall of lists of presented items, usually digits or letters, when irrelevant auditory material is presented together with the items to be memorized (Baddeley \& Salame, 1986; Colle \& Welsh, 1976; Jones, 1994; Jones \& Macken, 1995a, 1995b; Jones, Madden, \& Miles, 1992a, 1992b; Salame \& Baddeley, 1982, 1986). This effect occurs despite the fact that the irrelevant speech is independent of the serial recall task and despite the fact that subjects are explicitly instructed to ignore the speech (Jones, 1993). The effect also occurs regardless of whether the

\footnotetext{
An abstract of this paper has been previously published at the 8th International Conference on Functional Mapping of the Human Brain, 2-6 June 2002, Sendai, Japan.

* Corresponding author. Tel.: +31-24-3610658/+46-8-51772039/ +46-70-5745798 (mobile); fax: +31-24-3610652/+46-8-344146.

E-mail address: karl.magnus.petersson@ @cdonders.kun.nl (K.M. Petersson)
}

items to be memorized are presented visually (Salame \& Baddeley, 1982) or auditorily (Hanley \& Broadbent, 1987), regardless of whether the irrelevant speech occurs at presentation or during the retention interval (Miles, Jones, \& Madden, 1991), whether it comprises meaningful or meaningless information (Colle \& Welsh, 1976; Jones, Miles, \& Page, 1990; LeCompte, 1994; Salame \& Baddeley, 1989) or even if the irrelevant speech is being played backwards (Jones et al., 1990). However, the effect appears not to be a simple distraction, since loud bursts of noise have little or no effect on the serial recall task (Colle, 1980; Salame \& Baddeley, 1987).

There is no general agreement on the theoretical interpretation of the irrelevant speech effect. It is clearly not due to simple masking effects as irrelevant items that are similar in sound to the remembered material cause no more disruption than dissimilar irrelevant sounds (Jones \& Macken, 1995a, 1995b; Larsen, Baddeley, \& Andrade, 2000; LeCompte \& Shaibe, 1997; Surprenant, Neath, \& LeCompte, 1999). There is also a broad agreement with the 
view that disruption occurs principally when the irrelevant sound fluctuates, termed the 'changing-state hypothesis' by Jones (Jones, 1993; Jones et al., 1992a, 1992b; Jones \& Tremblay, 2000). A related phenomenon is the observation that repeating a single item impairs memory much less than do multiple items (Banbury, Macken, Tremblay, \& Jones, 2001; Jones \& Macken, 1993). The effect principally influences the storage of the order in which items are presented rather than the items themselves (Banbury et al., 2001; Jones, 1993), although some disruption has occasionally been observed when recall of order was not required (LeCompte, 1994, 1996).

Detailed interpretation remains controversial. Jones (Jones, 1993; Jones \& Tremblay, 2000) suggests the sound disrupts cues to serial order in multi-modal short-term memory system. Neath (Neath, 2000) gives an account in terms of the Nairne (Nairne, 1990) feature model, with the irrelevant sound disrupting the features that underpin recall. Baddeley interprets the effect in terms of the phonological loop component of working memory, while leaving the precise mechanism of disruption unspecified (Baddeley, 2000; Larsen \& Baddeley, in press).

\subsection{Working memory}

Working memory is a cognitive system that is thought to subserve the temporary storage and manipulation of new information in the course of performing many higher cognitive functions, such as reasoning, language comprehension, and visuo-spatial problem solving (Baddeley, 1986). According to Baddeley's model, working memory is divided into three major components: the phonological loop, which is a buffer specialized for storing verbal material, presumably in some form of phonological representation; the visuo-spatial sketch pad, which is another short-term memory buffer specialized for visuo-spatial material; and a central executive that supervises and coordinates the two buffers and utilizes the information contained in them for further manipulation or processing. It has been argued that the irrelevant speech effect, in addition to the phonological similarity effect, the word-length effect, as well as the phenomenon of articulatory suppression support the existence of two subcomponents of the phonological loop-the articulatory rehearsal process and the short-term phonological store (Baddeley \& Salame, 1986; Baddeley, 1992). A primary function of the phonological loop is the processing of novel speech input, that is, to support the long-term learning of the phonological forms of words in the native language (Baddeley, Papagno, \& Vallar, 1988; Baddeley, Gathercole, \& Papagno, 1998; Papagno \& Vallar, 1992).

Several functional neuroimaging studies indicate that the subsystems of working memory are associated with different neuroanatomical substrates, with the spatial system localized more dominantly in the right hemisphere, and the verbal system more in the left hemisphere (e.g. Smith \& Jonides, 1997). Within these systems, separable components seem to be responsible for the passive storage of information and the active maintenance of information, with the storage component being more closely related to the posterior parts of the brain, while it has been suggested that the active maintenance component is related to the frontal cortex (Smith \& Jonides, 1997). For example, positron emission tomography (PET) and fMRI studies lend support to the identification of the phonological store in the superior temporal cortex and the left inferior parietal region (Brodmann's area (BA) 39/40) and the articulatory rehearsal process involving a left frontal circuit including Broca's area (BA 44/45) and the premotor cortex (BA 6) (Awh et al., 1996; Ghatan, Hsieh, Petersson, StoneElander, \& Ingvar, 1998; Paulesu, Frith, \& Frackowiak, 1993; Schumacher et al., 1996; Smith \& Jonides, 1999; Smith, Jonides, \& Koeppe, 1996). On the other hand, visuo-spatial working memory is thought to be mediated by a network of predominantly right lateralized regions that include areas in posterior parietal, occipital, and frontal cortex, with posterior parietal and premotor regions subserving spatial storage (Smith \& Jonides, 1998, 1999). Both non-human and human neurophysiological studies support the notion that the executive function of working memory is subserved in part by a complex network within dorsolateral prefrontal cortex supporting the temporary retention and manipulation of particular types of material (D'Esposito \& Grossman, 1996). In general, prefrontal cortex has frequently been assigned an important role in working memory (D'Esposito et al., 1995; Haxby, Ungerleider, Horwitz, Rapoport, \& Grady, 1995; Jonides et al., 1993; Paulesu et al., 1993; Petrides, Alivisatos, Meyer, \& Evans, 1993; Raichle, 1994).

In the present study, we report the results of a behavioral and a positron emission tomography experiment. The behavioral experiment was carried out in order to test the experimental design and to verify the irrelevant speech effect. Subsequently, we investigated the irrelevant speech effect in a corresponding PET experiment in order to characterize the relative regional cerebral blood flow (rCBF) changes in a sample of normal subjects performing an immediate serial recall task under the influence of irrelevant speech. In a typical behavioral experiment of the irrelevant speech effect, the performance in speech conditions is compared to that in the quiet conditions. However, comparing speech conditions with quiet conditions would probably not serve as the most relevant measure of the irrelevant speech effect, since the tasks are not matched with respect to auditory input. Thus, the study was designed specifically to allow an analysis of the irrelevant speech effect between the presentation of single irrelevant items (expected to have little effect on memory), and multiple items (expected to impair recall), as an interaction contrast in the general linear model. The primary objective of the study was to investigate and characterize how the human brain responds differentially in a context when speech interferes with the retention of visually presented material in general and to explore the neural correlates of the irrelevant speech effect in particular. We frame these 
investigations within the functional model of verbal working memory and corresponding brain regions outlined above.

\section{Behavioral experiment}

In order to establish a reliable irrelevant speech effect a relatively large subject sample is generally required. To ensure that the standard effect was in fact occurring and to demonstrate that the conditions used in the present study were sufficient to produce it, we conducted a behavioral experiment in which the standard irrelevant speech paradigm was employed.

\section{Materials and methods}

\subsection{Subjects}

Thirty subjects (mean age $\sim 25$ years, range: $20-35$ ) participated in the behavioral study. All subjects were naive as to the literature on irrelevant speech effects and to the specific hypotheses being investigated in our study. Subjects were informed that a subset of participants would be selected and asked to participate in a re-test session in the PET-scanner a few weeks later.

\subsection{Stimuli}

Each set of visual stimuli consisted of six different lists of eight randomly chosen digits (1-9). The software MacStim (David Darby, http://porkpie.loni.ucla.edu/WhiteAnt/) was used for digit presentation at the center of an Apple Power Macintosh G3 computer screen in 80-point Geneva font in black on a white background. The digits appeared between 500 and $800 \mathrm{~ms}$ in each different subsets of the experiment and were presented with a frequency of $1 \mathrm{digit} / \mathrm{s}$. The irrelevant speech was auditorily presented with headphones. In the single item condition the same pseudo-word was repeatedly presented and in the multiple item condition seven phonologically dissimilar pseudo-words were presented in randomized order. The different pseudo-words consisted of three-letter words with a phonemic CVC syllable structure. In the single item condition both $\mathrm{CV}$ - and $\mathrm{CVC}$-structures were used in different subsets of the experiment. The auditory items were recorded and presented at a frequency of about $1 \mathrm{item} / \mathrm{s}$. The serial recall performance of the subjects was recorded with a Macintosh standard microphone attached to the computer and stored on the hard disk as System 7 sounds. The microphone was automatically on- and offset with the time for recall that lasted for $5.5 \mathrm{~s}$.

\subsection{Procedure}

The subjects engaged in six encoding-recall cycles with six corresponding lists of digits. Each condition was repeated twice and two sets of lists were used for each condition. First the word "Ready" was displayed on the computer screen and then a list of digits was sequentially presented. After $5.5 \mathrm{~s}$ for recall the word "Ready" appeared again and the next list was presented. The onset of the auditory items and the digits were not systematically related. Subjects were instructed to ignore the sounds presented over the headphones. Different subsets of subjects were subjected to different modifications of the visual as well as the auditory stimuli. The subjects were instructed to guess or to respond "pass" when they were unable to recall the digit for a given position. Additionally, the varied auditory items comprised different phonemic structures and were presented in different voices.

\subsection{Results and discussion}

Recall of digits was scored according to serial position giving one point for the right digit in the right place and zero for a wrong digit or "pass". The main finding of the pilot was that the irrelevant speech effect was evident in all modifications (different versions) of the behavioral paradigm indicating the robustness of the phenomenon. Fig. 1A displays the composite result of the performance for the sub-sample of subjects selected for the PET experiment (see below for selection criteria). The average performance was $74 \%$ ( \pm 4S.E.) in the quiet condition, $77 \%$ ( \pm 2 S.E.) in the single item condition and $68 \%( \pm 2$ S.E. $)$ in the multiple item condition. The results are consistent with the literature (Jones \& Morris, 1992; Salame \& Baddeley, 1982), with the multiple items having a disrupting effect on serial recall over all serial positions except for the third and fourth position compared to the quiet condition (Fig. 1B). Also consistent with previous findings (Jones \& Macken, 1993; LeCompte, 1995) the multiple items produced more disruption than the single items did. The literature on irrelevant speech effects between single items and quiet conditions are somewhat mixed. Effects have been demonstrated with a repeated sound and even with a similar continuous sound compared to quiet in some experiments (Jones et al., 1992a, 1992b; LeCompte, 1995) while in others no reliable effect have been observed (Jones, 1994; Jones \& Macken, 1995a,1995b).

\section{PET experiment}

The list length was reduced from eight to six digits in the PET experiment in order to decrease performance differences between conditions, and more importantly, potential neuronal/rCBF ceiling effects as potential confounding or otherwise limiting factors, thereby ensuring that we were operating in the linear range for relative $\mathrm{rCBF}$ changes. ERP data indicate that irrelevant speech influences brain activity despite the absence of a corresponding performance effect (Martin-Loeches, Schweinberger \& Sommer, 1997). Also, according to Lavie's law of attention (Lavie, 1995) supported by recent neuroimaging data (Rees, Frith, \& Lavie, 

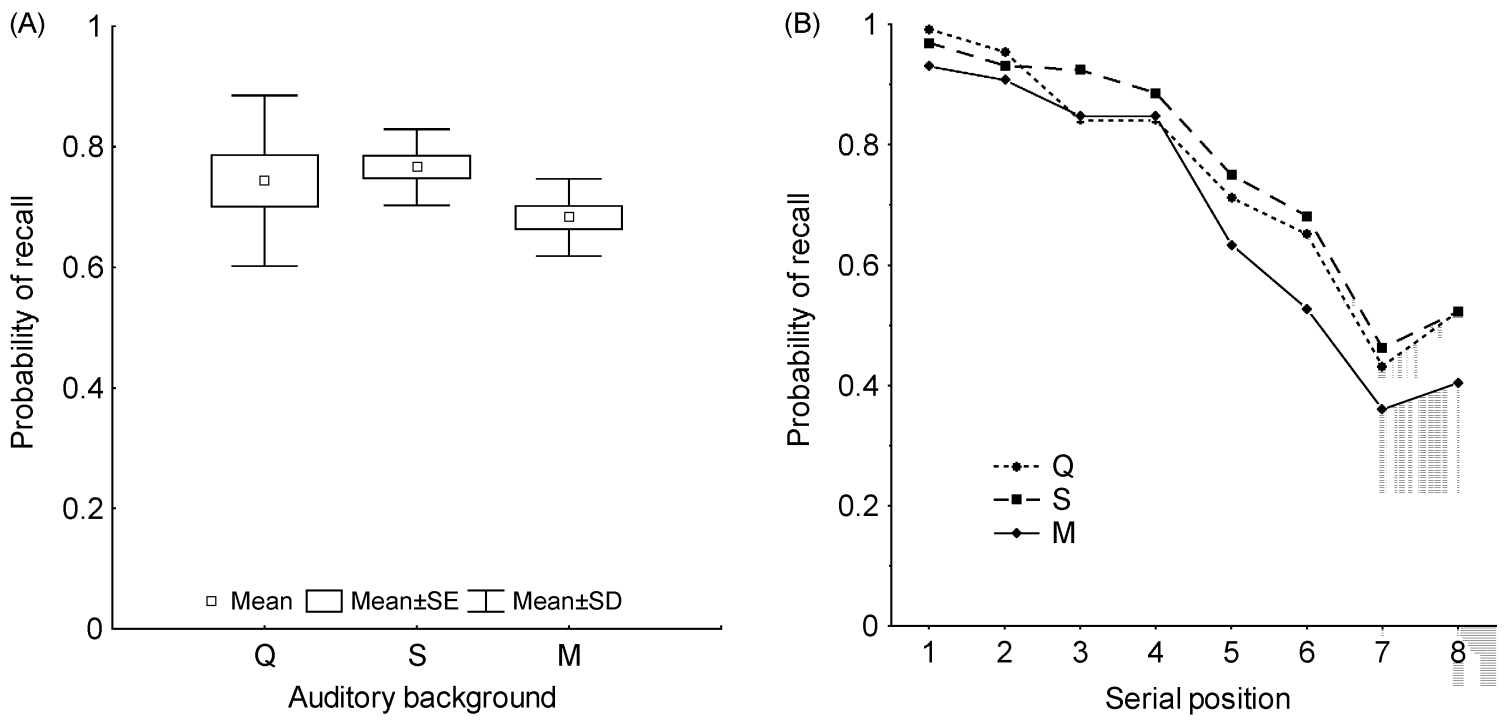

Fig. 1. Composite behavioral pilot data for the participants selected for the PET experiment. (A) Probability of serial recall errors in 12 trials across 11 subjects. (B) Serial position curves are plotted for quiet (Q), single item (S), and multiple item (M) auditory backgrounds.

1997; Rees, Frith, \& Lavie, 2001), participants' intention to ignore irrelevant distractors is not sufficient to avoid processing them, in other words, distractors are always processed whenever there is capacity available for processing.

\section{Materials and methods}

\subsection{Subjects}

Eleven right-handed (Edinburgh handedness inventory; Oldfield, 1971), healthy male subjects (mean age 25 years; range: 20-31) were included in the PET study. These subjects were selected from the participants of the behavioral study, to ensure roughly equivalent short-term memory span (10-40\% errors in the single pseudo-word condition) and thus to provide a fairly homogenous group with respect to working memory capacity. In addition, the subjects were pre-screened, ensuring that none used any medication, had a history of drug abuse (including nicotine), head trauma, neurological or psychiatric illness, or family history of neurological or psychiatric illness. The subjects had 1-5 years of university level education. The study was approved by the local Ethics and Radiation Safety Committees at the Karolinska Hospital. Informed consent was given by all the subjects.

\subsection{Stimuli}

Each condition was repeated twice and two sets of lists were used for each condition. Each set consisted of six lists. The software and stimulus characteristics were the same as described in the behavioral experiment. Each digit was shown $0.5 \mathrm{~s}$ and the inter-digit interval was $0.5 \mathrm{~s}$. The time for recall was $4 \mathrm{~s}$. The irrelevant speech (i.e. the CV-pseudo-words) was auditorily presented with head- phones at a level of $65 \mathrm{~dB}$ as measured by a Brüel \& Kjær (type 2235) artificial ear. The pseudo-words were recorded and edited in SoundEdit version 2 with 16-bit resolution and a $22 \mathrm{kHz}$ sampling rate. The digitized speech sounds were normalized to its maximum distortion-free value and passed through a high-pass filter to emphasize high frequencies. Fade-in and fade-out were used to avoid audible clicks at on- and offset of the individual speech sounds. The serial recall of the subjects was recorded with a Macintosh standard microphone attached to the computer and stored on the hard disk as System 7 sounds. The irrelevant speech in the single item condition consisted of repetitions of the identical CV-pseudo-word "da" [da:], while the CV-pseudo-words ne [ne], li [li], to [tu:], vu [vu], py [py], bå [bo:], nö [nœ:] were used at the multiple item condition in a randomized order. Both the single as well as the multiple CVs were electronically copied and presented at a frequency of 1 pseudo-word/s. The duration of the different CV-pseudo-words was $550 \pm 40 \mathrm{~ms}$ (mean \pm S.D.) and the duration of the single CV-pseudo-word was $550 \mathrm{~ms}$. The onset of the CVs and the digits were not systematically related. Subjects were instructed to ignore any sounds presented in the headphones.

\subsection{Cognitive activation paradigm and procedures-serial recall and serial repetition}

Subjects were scanned in the presence of ambient low background noise and dimmed lighting. Stimuli were presented on a $14 \mathrm{in}$. computer screen mounted at a viewing distance of approximately $50 \mathrm{~cm}$. The experimental paradigm consisted of a $2 \times 3$ factorial design, including two tasks of different memory load: immediate serial recall of different digit sequences (R) and immediate serial repetition of the standard digit sequence from one to six (C) at 
three different levels of irrelevant speech: quiet $(\mathrm{Q})$, single CV-pseudo-word (S), and multiple CV-pseudo-words (M). The subjects engaged in six encoding-recall cycles. After the word "Ready" was displayed on the computer screen, a list was presented. The digits were recalled immediately in serial order after encoding. During recall, six dots $(\ldots \ldots)$ were shown on the screen. Subjects were instructed to recall the visually presented digits by serial recall of the digits one by one through eye monitoring each dot when simultaneously recalling a digit in the corresponding serial position. By using the dots in this way subjects were able to keep track of how many digits were recalled and how many were left to recall. Subjects were instructed to memorize the digits in triplets, that is, groups of three digits and to say "pass" when they were unable to recall the digit for a given position. After four seconds the word "Ready" appeared again and the next list was serially presented. Each scan covered approximately five encoding-recall cycles (cf. below). Serving as a control condition, the serial repetition task consisted of repeating the digits 1-6 shown in a straightforward order. When all six digits had been presented the six dots were displayed on the computer screen and the subjects were instructed to repeat the digits overtly before the dots disappeared and the word "Ready" appeared again. The same stimulus presentation and interval times were used in the serial repetition as in the serial recall task, as well as the number of lists presented. The subjects practiced all aspects of the experimental paradigm (with sham injections) for approximately $20 \mathrm{~min}$ in the PET scanner before the experiment started. The subjects were asked not to move their mouths and tongues during the presentation of the digits, but they were allowed covert rehearsal. The six conditions were presented in a randomized order and repeated in two blocks. After the last scan the subjects were debriefed and asked about their mnemonic strategy.

\subsection{PET scanning and image data acquisition}

Each subject underwent 12 measurements of rCBF with a three-dimensional (3D) ECAT EXACT HR PET scanner (Wienhard et al., 1994) and bolus injections of [15-O] water (Fox \& Mintun, 1989; Fox, Perlmutter, \& Raichle, 1985). The PET scanner was used in 3D-sampling mode producing 60 s tracer uptake images. The different tasks were started at the time of tracer injection and the scanning was automatically initiated when the brain radioactivity exceeded a predetermined level above background. Scatter correction was made and a two-dimensional (2D)-transmission scan was used for attenuation correction.

\subsection{Image data preprocessing and statistical analysis}

The PET images were realigned, spatially normalized and transformed into a common stereotactic space as defined by the SPM99 template, an approximate Talairach space (Talairach \& Tournoux, 1988), 3D isotropic Gaussian filtered (14 mm FWHM), proportionally scaled to account for global confounders, and analyzed with the SPM99 software (Wellcome Department of Cognitive Neurology, http://www.fil.ion.ucl.ac.uk/spm/) running under MATLAB 5.3 (The Mathworks Inc., Sherbourn, MA). Non-specific approximately linear monotone time effects were modeled as covariates of no-interest using scan order in the general linear model. To test hypotheses about regionally specific condition effects, estimates were compared using linear contrasts, generating a $t$-statistic image $\operatorname{SPM}[t]$ using a fixed effects model. Our primary regions of interest related to brain regions, mainly the left hemisphere (Smith et al., 1996), that previously have been shown to be involved in verbal working memory, that is, the superior temporal cortex (BA 22/41/42) (Ghatan et al., 1998; Paulesu et al., 1993), the inferior parietal cortex (BA 39/40) (Awh, Smith, \& Jonides, 1995; Jonides et al., 1998), the ventrolateral prefrontal cortex (BA 44/45) (Awh et al., 1996; Burton, 2001; Schumacher et al., 1996; Smith \& Jonides, 1999) as well as the premotor (BA 6) (Awh et al., 1996; Smith \& Jonides, 1999) and supplementary motor areas (medial part of BA 6) (Schumacher et al., 1996; Smith \& Jonides, 1999). When referring to these regions of interests, activations were thresholded at $Z=3.05$ (or omnibus significance $P=0.001)$. Otherwise, $P$-values were corrected $(\alpha=0.05)$ for multiple non-independent comparisons based on the theory of smooth T random fields (Worsley et al., 1996). The activated regions were then characterized in terms of spatial extent and peak-height of local maxima. Attempts have been made to take into account the differences between the template used in SPM99 and the brain in the Talaraich atlas by utilizing the Talairach Space Utility (Positron Emission Tomography Lab of the Institute of the Human Brain, http:// www.ihb.spb.ru/ pet_lab/TSU/TSUMain.html) in complement with the MNI Space Utility (Positron Emission Tomography Lab of the Institute of the Human Brain, http://www. ihb.spb.ru/ pet_lab/MSU/MSUMain.html), both of which adopt a non-linear transformations approach, as described at the MRC CBU Imaging website (http://www.mrccbu.cam.ac.uk/Imaging).

\section{Results}

\subsection{Behavioral performance data}

The recalled digits were scored according to their serial positions as described in the pilot. Data for two of the 11 subjects were lost due to technical failure. Fig. 2A displays the performance data during the PET scans. Scored as probability of recall the average was $93 \%( \pm 2$ S.E. $)$ in the quiet condition, $91 \%$ ( \pm 3 S.E.) in the single item, and $92 \%$ ( \pm 3 S.E. $)$ in the multiple item condition. A multiple regression analysis revealed no significant differences between conditions $(F[1,25]=0.147, P=0.70)$. The post-experimental debriefing concerning the cognitive 

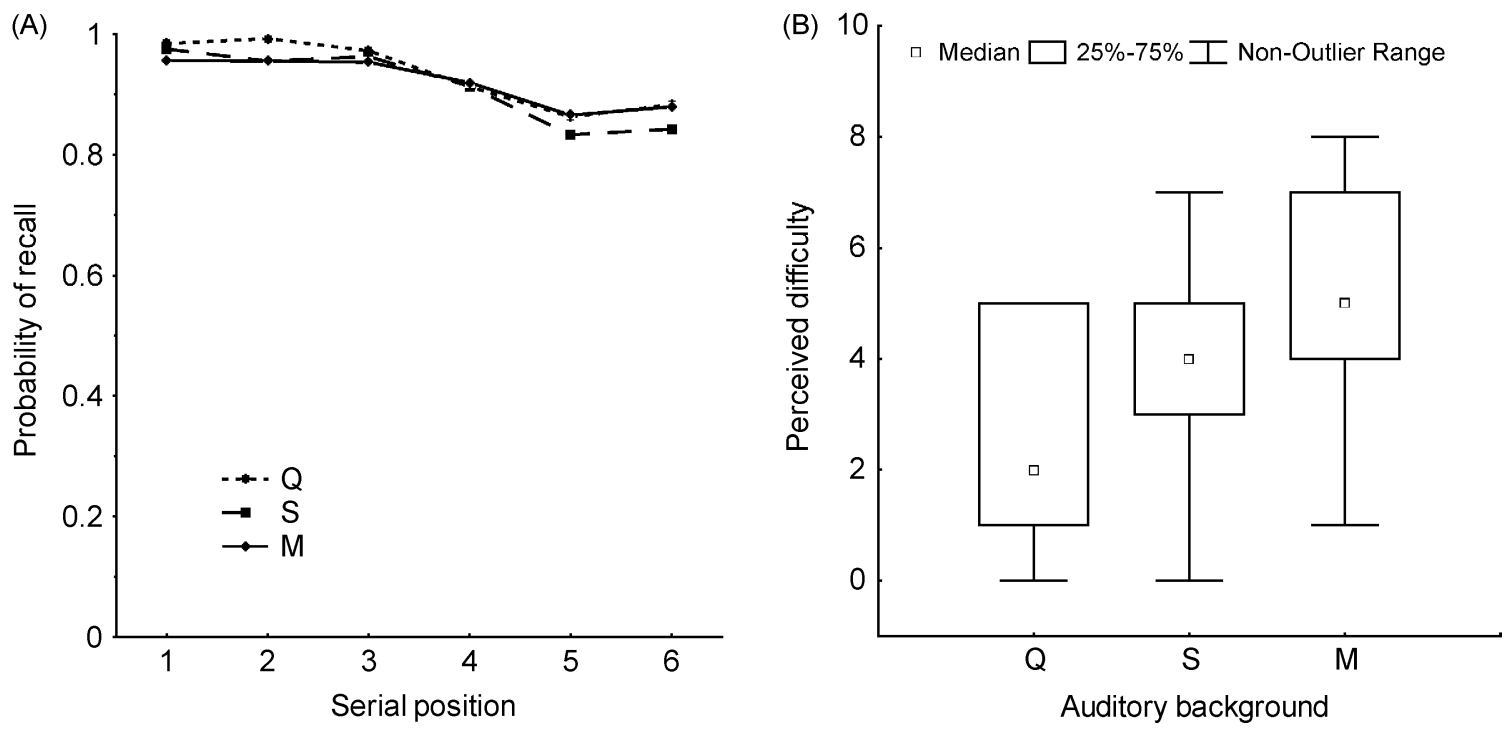

Fig. 2. (A) The irrelevant speech effect during the PET experiment displayed as serial position curves for quiet (Q), single item (S), and multiple item (M) conditions in 12 trials across nine subjects. (B) Subjective ratings from the post-experimental interview comparing the perceived difficulty during serial recall in the auditory conditions.

strategies in the PET experiment indicated that most of the subjects recalled the digits in triplets as suggested to them during the practice session. However, five subjects explicitly reported to use a visual strategy for the last $1-3$ digits of the sequence. Rating the degree of difficulty of the three different auditory conditions from 0 to 10 , all subjects rated the multiple item condition to be harder than the single item condition except for two subjects that estimated them to be of equal difficulty. The median of the ratings for the different auditory conditions were $\mathrm{Q}=2, \mathrm{~S}=4$ and $\mathrm{M}=5$ (Fig. 2B).

\subsection{PET data}

\subsubsection{Working memory effects}

We examined the main effect of working memory by combining the results from the three serial recall tasks and comparing them with the control tasks ([RM + RS + RQ] $-[\mathrm{CM}+\mathrm{CS}+\mathrm{CQ}])$. This analysis revealed significant increases of blood flow in the left inferior frontal cortex (BA $6, Z=6.63$ ), the left anterior cingulate cortex (BA $32, Z=7.39$ and 7.14$)$ and the bilateral anterior insular cortices $(Z=5.75$ and 4.25$)$, on the left extending into the lentiform nucleus ( $Z=5.65$ and 5.32) (Table 1). Parietal increases were observed in the left parietal cortex (BA $40 / 7, Z=4.91$ ) and the right precuneus (BA $7, Z=5.44$ ). Additional subcortical activations were present in the left thalamus $(Z=4.51)$ and the bilateral cerebellum ( $Z$ scores between 5.31 and 7.08). Several different regions of decreased activity were also observed in the working memory related contrast. Decreases were present in the bilateral inferior prefrontal cortices (BA 47, Z scores between 5.09 and 6.09), the right/bilateral superior medial frontal cortex (BA 8 and $9, Z=7.81$ and 7.57), and the right posterior cingulate cortex (BA 31, $Z=$ inf) (Table 2). Additional activity was observed in the right middle-superior temporal regions (BA 22, $Z=4.28$ and 4.93).

6.2.1.1. The main effect of irrelevant speech. When comparing irrelevant speech to quiet in conditions of serial recall $(\mathrm{RM}+\mathrm{RS}-2 \mathrm{RQ})$ increases of $\mathrm{rCBF}$ were confined to the bilateral superior temporal regions (BA 41 and $22, Z$ scores ranging between 4.74 and 7.55; Table 3). No significant decreases of activity were present in the reverse contrast.

6.2.1.2. The irrelevant speech effect. When investigating the interaction between the level of irrelevant speech (multiple and single items) and working memory load ([RM-CM] $-[$ RS-CS]), relative decreases of blood flow were centered in the left superior temporal cortex (BA 22, $Z=3.95$; Fig. 3) and in the right inferior/middle frontal cortex (BA 6/9/44, $Z=3.31$; Table 4; Fig. 4). Inspection of the activation images (Fig. 5) suggests that there were additional decreases of activity of homologous sites in the contralateral hemisphere, including the right superior temporal cortex (BA 42/22, [60, $-10,10], Z=1.97$ and BA $42,[56,-30,8], Z=1.43$ ) and the left inferior/middle frontal cortex (BA 6/9/44, [-42, $6,34], Z=2.49$ ) as well as additional activation in the left inferior parietal cortex (BA 40, [-44, -48, 42], $Z=1.70$ ), although these effects were statistically weak (uncorrected $P<0.1$ ). No significant increases of activity were present in the reverse contrast.

\section{Discussion}

The primary objective of this study was to investigate and characterize the irrelevant speech effect in a PET experiment 
Table 1

Local maxima of activations observed in the verbal working memory main effect comparison (RM $+\mathrm{RS}+\mathrm{RQ})-(\mathrm{CM}+\mathrm{CS}+\mathrm{CQ})$ : foci of significant $\mathrm{rCBF}$ increases

\begin{tabular}{|c|c|c|c|c|c|c|}
\hline \multirow[t]{2}{*}{ Region of activation } & \multirow[t]{2}{*}{ Left/right } & \multirow[t]{2}{*}{ Brodmann's area } & \multicolumn{3}{|c|}{ Talairach coordinates } & \multirow[t]{2}{*}{$Z$ score } \\
\hline & & & $x$ & $y$ & $z$ & \\
\hline Inferior frontal cortex & $\mathrm{L}$ & $6 / 44$ & -48 & 0 & 32 & 6.63 \\
\hline Anterior cingulate cortex & $\begin{array}{l}\mathrm{L} \\
\mathrm{L}\end{array}$ & $\begin{array}{l}32 \\
32\end{array}$ & $\begin{array}{l}-4 \\
-2\end{array}$ & $\begin{array}{l}10 \\
14\end{array}$ & $\begin{array}{l}42 \\
34\end{array}$ & $\begin{array}{l}7.39 \\
7.14\end{array}$ \\
\hline $\begin{array}{l}\text { Inferior parietal cortex } \\
\text { Precuneus }\end{array}$ & $\begin{array}{l}\mathrm{L} \\
\mathrm{R}\end{array}$ & $\begin{array}{r}40 \\
7\end{array}$ & $\begin{array}{r}-38 \\
4\end{array}$ & $\begin{array}{l}-50 \\
-70\end{array}$ & $\begin{array}{l}46 \\
50\end{array}$ & $\begin{array}{l}4.91 \\
5.44\end{array}$ \\
\hline Anterior insular cortex & $\begin{array}{l}\mathrm{L} \\
\mathrm{R}\end{array}$ & & $\begin{array}{r}-34 \\
34\end{array}$ & $\begin{array}{l}16 \\
16\end{array}$ & $\begin{array}{l}4 \\
0\end{array}$ & $\begin{array}{l}5.75 \\
4.25\end{array}$ \\
\hline $\begin{array}{l}\text { Lentiform nucleus (Putamen) } \\
\text { Lentiform nucleus (Putamen) } \\
\text { Thalamus }\end{array}$ & $\begin{array}{l}\mathrm{L} \\
\mathrm{L} \\
\mathrm{L}\end{array}$ & & $\begin{array}{r}-22 \\
-24 \\
-8\end{array}$ & $\begin{array}{r}4 \\
12 \\
-20\end{array}$ & $\begin{array}{r}-2 \\
0 \\
8\end{array}$ & $\begin{array}{l}5.65 \\
5.32 \\
4.51\end{array}$ \\
\hline Cerebellum & $\begin{array}{l}\mathrm{L} \\
\mathrm{L} \\
\mathrm{L} \\
\mathrm{R} \\
\mathrm{R} \\
\mathrm{R}\end{array}$ & & $\begin{array}{r}-4 \\
-22 \\
-10 \\
4 \\
4 \\
26\end{array}$ & $\begin{array}{l}-74 \\
-60 \\
-68 \\
-72 \\
-74 \\
-60\end{array}$ & $\begin{array}{l}-24 \\
-28 \\
-24 \\
-26 \\
-10 \\
-26\end{array}$ & $\begin{array}{l}6.52 \\
5.53 \\
5.31 \\
7.08 \\
6.02 \\
5.58\end{array}$ \\
\hline
\end{tabular}

The coordinates of the foci of maximal significant change of $\mathrm{rCBF}(P<0.001$ uncorrected $)$ in the standard stereotactic space of Talairach \& Tournoux, 1988. $Z$ scores greater than 3.94 corresponding to $P<0.05$ corrected are in bold type.

Table 2

Local maxima of activations observed in the verbal working memory main effect comparison $(C M+C S+C Q)-(R M+R S+R Q)$ : foci of significant rCBF decreases

\begin{tabular}{|c|c|c|c|c|c|c|}
\hline \multirow[t]{2}{*}{ Region of activation } & \multirow[t]{2}{*}{ Left/right } & \multirow[t]{2}{*}{ Brodmann's area } & \multicolumn{3}{|c|}{ Talairach coordinates } & \multirow[t]{2}{*}{$Z$ score } \\
\hline & & & $x$ & $y$ & $z$ & \\
\hline \multirow[t]{4}{*}{ Inferior prefrontal cortex } & $\mathrm{L}$ & 47 & -40 & 16 & -18 & 5.12 \\
\hline & $\mathrm{R}$ & 47 & 50 & 28 & -6 & 6.09 \\
\hline & $\mathrm{R}$ & 47 & 44 & 34 & -14 & 5.83 \\
\hline & $\mathrm{R}$ & 47 & 46 & 16 & -18 & 5.09 \\
\hline \multirow[t]{3}{*}{ Medial prefrontal cortex } & $\mathrm{R}$ & 8 & 4 & 38 & 42 & 7.81 \\
\hline & $\mathrm{R}$ & 8 & 8 & 32 & 46 & 7.57 \\
\hline & $\mathrm{L} / \mathrm{R}$ & 9 & 0 & 42 & 34 & 7.57 \\
\hline Posterior cingulate cortex & $\mathrm{R}$ & 31 & 4 & -48 & 30 & Inf \\
\hline Superior temporal cortex & $\mathrm{R}$ & 22 & 60 & -42 & 16 & 4.28 \\
\hline Middle/superior temporal cortex & $\mathrm{R}$ & 22 & 64 & -34 & 2 & 4.93 \\
\hline
\end{tabular}

Table 3

Local maxima of activations observed in the irrelevant speech main effect comparison ( $R M+R S-2 R Q)$ : foci of significant $r C B F$ increases

\begin{tabular}{|c|c|c|c|c|c|c|}
\hline \multirow[t]{2}{*}{ Region of activation } & \multirow[t]{2}{*}{ Left/right } & \multirow[t]{2}{*}{ Brodmann's area } & \multicolumn{3}{|c|}{ Talairach coordinates } & \multirow[t]{2}{*}{$Z$ score } \\
\hline & & & $x$ & $y$ & $z$ & \\
\hline \multirow[t]{6}{*}{ Superior temporal cortex } & $\mathrm{L}$ & 22 & -54 & -18 & 2 & 7.35 \\
\hline & $\mathrm{L}$ & 22 & -56 & -34 & 6 & 5.84 \\
\hline & $\mathrm{L}$ & 41 & -42 & -30 & 10 & 4.74 \\
\hline & $\mathrm{R}$ & 22 & 62 & -14 & 2 & 7.55 \\
\hline & $\mathrm{R}$ & 22 & 64 & -24 & 6 & 7.34 \\
\hline & $\mathrm{R}$ & 41 & 50 & -26 & 6 & 5.74 \\
\hline
\end{tabular}



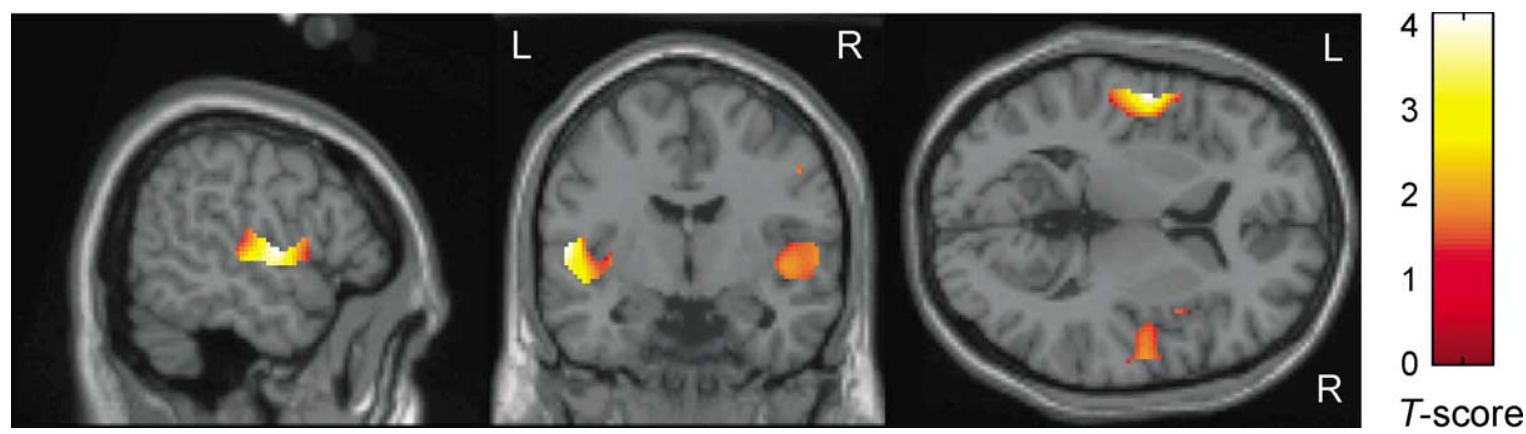

Fig. 3. The irrelevant speech interaction contrast. The relative decrease of $\mathrm{rCBF}$ in the bilateral superior temporal regions.

Table 4

The irrelevant speech contrast $(\mathrm{RM}-\mathrm{CM})-(\mathrm{RS}-\mathrm{CS})$. Relative decreases (i.e. local maxima in $[\mathrm{RS}-\mathrm{CS}]-[\mathrm{RM}-\mathrm{CM}])$ were observed in the left superior temporal and right inferior/middle frontal regions

\begin{tabular}{llrrrr}
\hline Region of activation & Left/right & Brodmann's area & & \multicolumn{2}{c}{ Talairach coordinates } \\
\cline { 5 - 7 } & & & $x$ & \multicolumn{2}{c}{$z$ score } \\
\hline Inferior/middle frontal cortex & $\mathrm{R}$ & $6 / 9 / 44$ & 54 & 2 & 32 \\
Superior temporal cortex & $\mathrm{L}$ & 22 & -54 & -6 & 6 \\
\hline
\end{tabular}

Foci approaching significance with a $Z$ score between 3.05 and 3.94 are given in plain type. $P$ values corrected for multiple comparisons are in bold type. Uncorrected $P$ values are in plain type.

and the main finding in relation to this objective was that the irrelevant speech effect appears to be correlated with and thus tentatively may be explained in terms of a distributed suppression of the components of the verbal working memory network. When exposed to irrelevant speech, processing appears broadly suppressed as indicated by a decrease of activity in bilateral secondary auditory and inferior/middle frontal areas as well as in the left inferior parietal cortex. The most prominent decrease of activity related to the irrel-

\section{Sup. Temporal $(-54,-6,6)$}

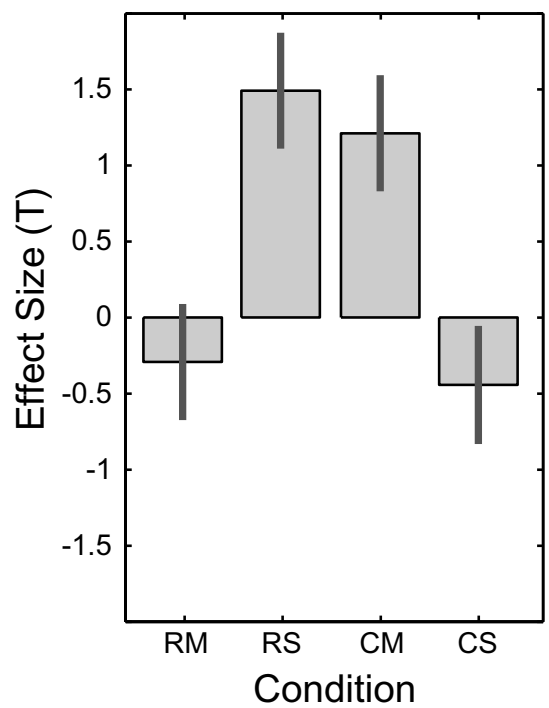

evant speech was observed in the middle portion of the left superior temporal cortex.

\subsection{Verbal working memory}

In the present study, the verbal short-term memory and control tasks differ mainly in the load placed on working memory. Therefore, subtracting the activation in the serial repetition tasks from the activation in the serial recall tasks

\section{R. Inf/Mid. Frontal (54, 2, 32)}

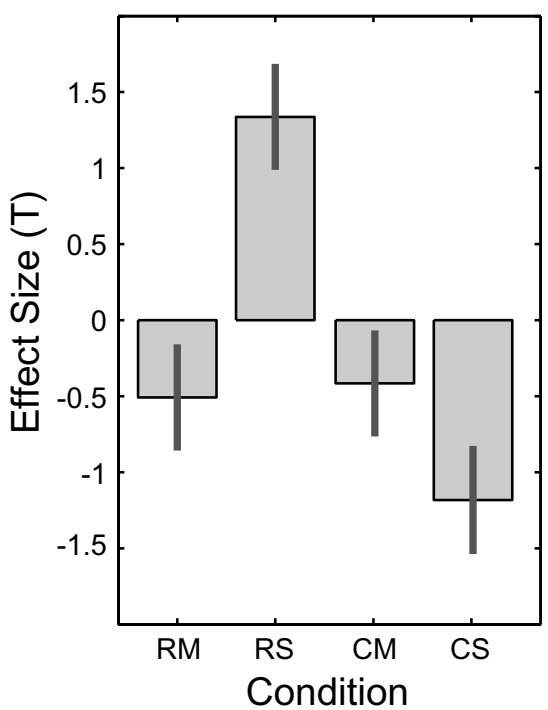

Fig. 4. The effect size for each condition in the left superior temporal cortex and the right inferior/middle frontal cortex presented in Table 4. Error bars indicate the standard error of the mean across subjects. RM: recall/multiple items, RS: recall/single item, CM: control/multiple items, CS: control/single item. Foci approaching significance with a $Z$ score between 3.05 and 3.94 are given in plain type. 

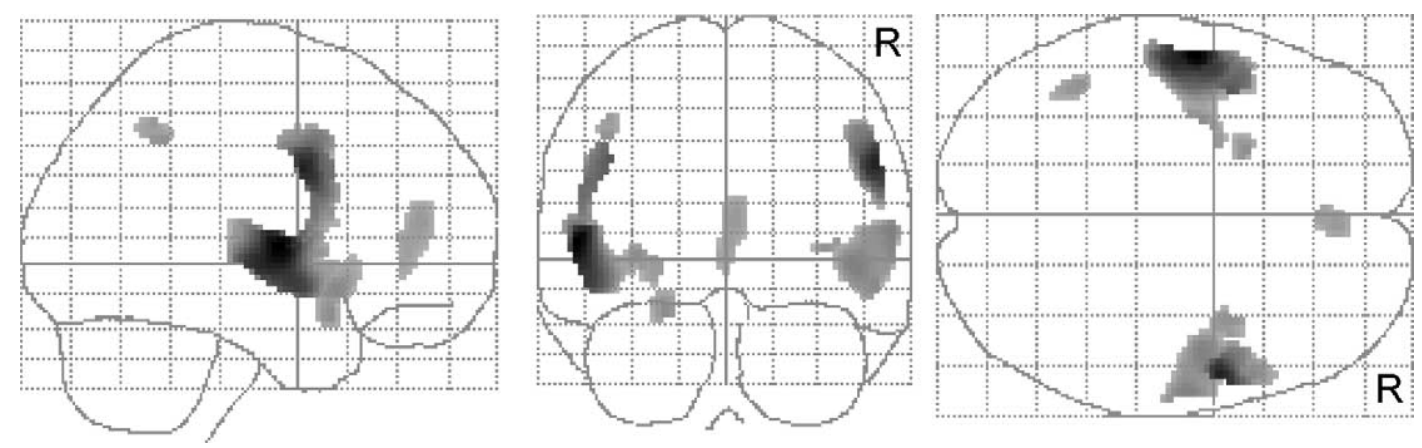

Fig. 5. Statistical parametric maps of relative decreases in the irrelevant speech contrast. For display purposes, pixels exceeding a threshold level of significance of $P<0.1$ uncorrected for multiple comparisons are displayed on sagittal, coronal and transverse projections of the brain (R: right). The coordinates of the foci of maximal change (uncorrected $P<0.001$ ) of rCBF are given in Table 4.

should reveal regions of the brain associated with verbal working memory. Tasks involving mainly the storage component and not so much the central executive system of verbal working memory, such as the item-recognition task (Awh et al., 1996; Paulesu et al., 1993; Smith, Jonides, Marshuetz, $\&$ Koeppe, 1998) or ' $n$-back' tasks with low working memory load (Jonides et al., 1997), typically produce activation bilaterally (left $>$ right) in premotor (BA 6), middle-inferior frontal (BA 44/45), posterior parietal (BA 7/40), and superior temporal (BA 22/42) regions, as well as the cerebellum (right $>$ left) (for review, see Smith \& Jonides, 1999). In addition, the anterior cingulate (Awh et al., 1996; D'Esposito et al., 1995; Smith et al., 1995) is usually activated in tasks with relatively high working memory load, suggesting that it reflects attentional aspects of central executive processing (D'Esposito et al., 1995) or, perhaps, task difficulty (Barch et al., 1997). Both the insula (Awh et al., 1996; Paulesu et al., 1993) and the basal ganglia (Braver et al., 1997; Monchi, Petrides, Petre, Worsley, \& Dagher, 2001) have also been observed in tasks involving working memory. In particular, it has been suggested that the insular cortex is an integral part of the phonological loop (Paulesu et al., 1993; Petersson, Reis, Askelof, Castro-Caldas, \& Ingvar, 2000). However, the more specific functional roles of these activations as related to working memory remain unclear (for reviews, see Cabeza \& Nyberg, 2000; Fletcher \& Henson, 2001). Consistent with previous neuroimaging research, verbal working memory related activations (Table 1) were localised to the left middle-inferior frontal cortex (BA 6/44) and the left anterior cingulate cortex (BA 32). Additional activations were present in the left inferior parietal cortex (BA 40), the right superior parietal cortex (BA 7), and the bilateral anterior insular cortices. Subcortical activations were observed in the left lentiform nucleus (a part of corpus striatum), the left thalamus as well as in the cerebellum bilaterally. A similar overall pattern of activations was also present in the simple main effect contrasts. Consequently, all of these regions are implicated in the distributed circuitry underlying working memory, fully consistent with previous functional imaging studies of verbal working memory, supporting the validity of our experimental design.

\subsection{The irrelevant speech effect}

The posterior superior temporal regions are the most consistently observed areas related to speech processing in functional imaging studies (Hickok \& Poeppel, 2000) and has been shown to be involved in both speech perception as well as speech production (Buchsbaum, Hickok, \& Humphries, 2001; Papathanassiou et al., 2000; Price et al., 1996). The superior temporal gyrus (BA 22/42) has been activated by tasks requiring phonological processing in the absence of auditory input (Paulesu et al., 1993). When comparing conditions of irrelevant speech to quiet, collapsing the different speech conditions in serial recall using quiet as a reference state, robust activations were detected in the superior temporal region (BA 22 and 41/42) bilaterally. Consistent with its important role in speech processing, the activation of this region in the present study is most likely due to the input of irrelevant speech, reflecting phonological processing of the meaningless phonetic-syllabic units.

In the above comparisons, as would in a typical behavioral experiment of the irrelevant speech effect, the performance in speech conditions is compared to that in the quiet conditions. However, comparing speech conditions with quiet conditions would probably not serve as the most relevant measure of the irrelevant speech effect, since the tasks are not matched with respect to auditory input. Thus, the study was designed specifically to allow an analysis of the irrelevant speech effect between the single items and multiple items as an interaction contrast in the general linear model. Using the two different speech conditions in the serial recall and serial repetition tasks (i.e. $[\mathrm{RM}-\mathrm{CM}]-[\mathrm{RS}-\mathrm{CS}]$ ), differences in activation patterns specifically related to irrelevant speech interacting with serial recall could be investigated. The main difference between the two speech conditions was the degree of phonological variability in the presented irrelevant speech items. Based on theoretical explanations (Jones et al., 1992a, 1992b; Banbury et al., 2001) as well as empirical findings (e.g. Jones \& Macken, 1993; LeCompte, 1995), the repetition of multiple items should produce more disruption than the repetition of a single item. However, in the PET experiment there were no significant performance differences 
between the single item and multiple item conditions, likely due to ceiling effects. Despite this absence of a behavioural difference a significant decrease of activation was observed in the left superior temporal cortex and a similar but weaker decreased activity in the right homologous area (Fig. 3). The superior temporal cortex, in addition to the inferior frontal (BA 44/45), supramarginal (BA 40) and the insular cortices, has been proposed to constitute the phonological loop in working memory (Paulesu et al., 1993; Petersson et al., 2000). Whether the superior temporal cortex is an integral part of the core verbal working memory network can be discussed. However, following its important role in phonological processing, we suggest that the decrease of activity in the superior temporal region reflect an active top-down suppression of early phonological processing (Ghatan et al., 1998).

It should be noted that the superior temporal region referred to by Paulesu et al. (1993), as well as the one reported in the main effect of irrelevant speech contrast (reflecting auditory input), is located posterior to the one found in the interaction contrast. This may reflect variability in study populations. Still, there is some lesion data as well as functional neuroimaging data indicating that the anterior-middle part of the superior temporal cortex is related to the processing of sequential aspects of language input (i.e. syntactic processing of language, cf. Bavelier et al., 1997; Dronkers, Wilkins, van Valin, Redfern, \& Jeager, 1994; Mazoyer et al., 1993). This may be related to the changing-state hypothesis of the irrelevant speech effect (Jones et al., 1992a, 1992b) suggesting that the effect arises through interference between the two concurrent processes of seriation (i.e. the maintenance of order). While this might suggest an effect operating through disruption of subvocal rehearsal, prevention of rehearsal does not remove the effect when material is presented auditorily, with irrelevant speech following (Hanley \& Broadbent, 1987; Hanley \& Bakopoulou, in press). It thus seems likely that disruption occurs at the level of storing or retrieving serial order cues.

The inferior parietal cortex and the inferior frontal cortex in the left hemisphere are regions closely linked to verbal working memory. The left inferior parietal region (BA 39/40) is suggested to be associated with the phonological store (Awh et al., 1995; Jonides et al., 1998; Paulesu et al., 1993), while a left middle-inferior frontal area including Broca's area (BA 44/45) and the premotor cortex (BA 6) have been associated with the articulatory rehearsal process (Awh et al., 1996; Braver et al., 1997; Paulesu et al., 1993; Schumacher et al., 1996; Smith et al., 1996, 1998). Premotor (BA 6) activations, however, have been observed for both verbal and non-verbal material as well as for a range of different tasks, and may therefore reflect more general working memory operations (Cabeza \& Nyberg, 2000). Consistent with the important roles of these areas in verbal working memory decreases of activity were observed in the middle-inferior frontal cortices bilaterally (BA 6/9/44), likely extending into Broca's area on the left (cf. Amunts et al., 1999). Weak activation in the left inferior parietal cor- tex (BA 40), suggests that the irrelevant speech effect may be related to a general disrupting inhibitory influence on phonological processing as reflected in these regions. The left inferior parietal activation is of particular importance from a theoretical perspective, since this region is suggested to reflect the phonological store, the subcomponent of the working memory model where the irrelevant speech effect is assumed to take place (Baddeley \& Salame, 1986; Baddeley, 1990, 1992, 1996; Jones \& Morris, 1992; Miles et al., 1991; Morris \& Jones, 1990). In keeping with the theoretical predictions of the primary locus of the irrelevant speech effect and consistent with neuroimaging data of verbal working memory, the left superior temporal gyrus might also be included in the functional anatomy of the phonological store.

Taken together, the reported activations and areas of decreased activity can be interpreted in terms of suppression of irrelevant areas consistent with previous findings (Ghatan et al., 1998). Decreases of activation were found in the bilateral (left $>$ right) superior temporal region, the bilateral inferior/middle frontal cortices (right $>$ left), as well as in the left inferior parietal cortex (Fig. 5), interpreted as a suppression of activity in functional components of the phonological loop (Paulesu et al., 1993; Smith \& Jonides, 1999).

\subsection{Attentional modulation}

The results from the interaction contrast can be discussed in terms of attentional modulation (Ghatan et al., 1998). Functional imaging studies have shown that activity in motion sensitive areas in the human brain (V5) is enhanced when subjects attend to motion rather than view moving stimuli passively (Corbetta, Miezin, Dobmeyer, Shulman, \& Petersen, 1991; Shulman et al., 1997) or even without moving stimuli (Chawla, Rees, \& Friston, 1999). These and similar findings suggest that attention modulates sensitivity of functionally specialized neuronal populations to inputs by changing background activity according to task instructions. Conversely, decreased activity may reflect suppression of neural activity in task-irrelevant modalities (Haxby et al., 1994; Shulman et al., 1997). In keeping with this hypothesis, the decreased activity observed in the secondary auditory areas (BA 22) might reflect top-down attentional inhibitory modulation of task-irrelevant processing (Ghatan et al., 1998).

\section{Conclusions}

In the present PET experiment, the activation pattern related to the main effect of verbal working memory was highly consistent with previous neuroimaging data supporting the validity of our experimental design. The results suggest that the irrelevant speech effect is correlated with and thus tentatively may be explained in terms of a distributed suppression of the components of the verbal working memory network as outlined. When exposed to 
irrelevant speech, processing appears broadly suppressed as indicated by a decrease of activity in bilateral secondary auditory and inferior/middle frontal areas as well as in the left inferior parietal cortex. The most prominent decrease of activity related to the irrelevant speech was observed in the middle portion of the left superior temporal cortex. The results can be interpreted in terms of inhibitory top-down attentional mechanisms attenuating the influence of the irrelevant speech. Although initial hypotheses about the neural correlates of the irrelevant speech effect have been posited, additional studies are clearly necessary to more fully characterize the nature of this phenomenon and its theoretical implications for existing short-term memory models.

\section{Acknowledgements}

This work was supported by grants from the Swedish Medical Research Council [8246], the Karolinska Institute, the Swedish Bank Tercentenary Foundation and the Knut and Alice Wallenberg Foundation.

\section{References}

Amunts, K., Schleicher, A., Burgel, U., Mohlberg, H., Uylings, H. B., \& Zilles, K. (1999). Broca's region revisited: cytoarchitecture and intersubject variability. Journal of Comparative Neurology, 412, 319341.

Awh, E., Smith, E. E., \& Jonides, J. (1995). Human rehearsal processes and the frontal lobes: PET evidence. Annals of the New York Academy of Sciences, 769, 97-117.

Awh, E., Jonides, J., Smith, E. E., Schumacher, E. H., Koeppe, R. A., \& Katz, S. (1996). Dissociation of storage and rehearsal in verbal working memory: evidence from positron emission tomography. Psychological Science, 7, 25-31.

Baddeley, A., \& Salame, P. (1986). The unattended speech effect: perception or memory? Journal of Experimental Psychology: Learning, Memory, \& Cognition, 12, 525-529.

Baddeley, A. (1986). Working memory. Oxford: Oxford University Press.

Baddeley, A. (1990). Human memory: Theory and practice. Hove and London: L. Erlbaum.

Baddeley, A. (1992). Working memory. Science, 255, 556-559.

Baddeley, A. (1996). Working memory: the interface between memory and cognition. In SE Gathercole (Ed.), Models of short-term memory. Hove, UK: Psychology Press.

Baddeley, A. D. (2000). The phonological loop and the irrelevant speech effect: some comments on Neath (2000). Psychonomic Bulletin \& Review, 7, 544-549.

Baddeley, A., Papagno, C., \& Vallar, G. (1988). When long-term learning depends on short-term storage. Journal of Memory \& Language, 27, 586-595.

Baddeley, A., Gathercole, S., \& Papagno, C. (1998). The phonological loop as a language learning device. Psychology Review, 105, 158-173.

Banbury, S. P., Macken, W. J., Tremblay, S., \& Jones, D. M. (2001). Auditory distraction and short-term memory: phenomena and practical implications. Human Factors, 43, 12-29.

Barch, D. M., Braver, T. S., Nystrom, L. E., Forman, S. D., Noll, D. C., \& Cohen, J. D. (1997). Dissociating working memory from task difficulty in human prefrontal cortex. Neuropsychologia, 35, 1373-1380.

Bavelier, D., Corina, D., Jezzard, P., Padmanabhan, S., Clark, V. P., \& Karni, A. et al., (1997). Sentence reading: a functional MRI study at 4 Tesla. Journal of Cognitive Neuroscience, 9, 664-686.
Braver, T. S., Cohen, J. D., Nystrom, L. E., Jonides, J., Smith, E. E., \& Noll, D. C. et al., (1997). A parametric study of prefrontal cortex involvement in human working memory. Neuroimage, 5, 49-62.

Buchsbaum, B. R., Hickok, G., \& Humphries, C. (2001). Role of left posterior superior temporal gyrus in phonological processing for speech perception and production. Cognitive Science, 25, 663-678.

Burton, M. W. (2001). The role of inferior frontal cortex in phonological processing. Cognitive Science, 25, 695-709.

Cabeza, R., \& Nyberg, L. (2000). Imaging cognition II: an empirical review of 275 PET and fMRI studies. Journal of Cognitive Neuroscience, 12, 1-47.

Chawla, D., Rees, G., \& Friston, K. J. (1999). The physiological basis of attentional modulation in extrastriate visual areas. Nature Neuroscience, 2, 671-676.

Colle, H. A., \& Welsh, A. (1976). Acoustic masking in primary memory. Journal of Verbal Learning and Verbal Behavior, 15, 17-32.

Colle, H. A. (1980). Auditory encoding in visual short-term recall: effects of noise intensity and spatial locations. Journal of Verbal Learning and Verbal Behavior, 19, 722-735.

Corbetta, M., Miezin, F. M., Dobmeyer, S., Shulman, G. L., \& Petersen, S. E. (1991). Selective and divided attention during visual discriminations of shape, color, and speed: functional anatomy by positron emission tomography. Journal of Neuroscience, 11, 2383-2402.

D'Esposito, M., \& Grossman, M. (1996). The physiological basis of executive function and working memory. The Neuroscientist, 2, 345352.

D’Esposito, M., Detre, J. A., Alsop, D. C., Shin, R. K., Atlas, S., \& Grossman, M. (1995). The neural basis of the central executive system of working memory. Nature, 378, 279-281.

Dronkers, N. F., Wilkins, D. P., van Valin, R. D., Redfern, B. B., \& Jeager, J. J. (1994). A reconsideration of the brain areas involved in the disruption of morphosyntactic comprehension. Brain \& Language, 47, 461-463.

Fletcher, P. C., \& Henson, R. N. (2001). Frontal lobes and human memory: insights from functional neuroimaging. Brain, 124, 849-881.

Fox, P. T., \& Mintun, M. A. (1989). Noninvasive functional brain mapping by change-distribution analysis of averaged PET images of H215O tissue activity. Journal of Nuclear Medicine, 30, 141-149.

Fox, P. T., Perlmutter, J. S., \& Raichle, M. E. (1985). A stereotactic method of anatomical localization for positron emission tomography. Journal of Computer Assisted Tomography, 9, 141-153.

Ghatan, P. H., Hsieh, J. C., Petersson, K. M., Stone-Elander, S., \& Ingvar, M. (1998). Coexistence of attention-based facilitation and inhibition in the human cortex. Neuroimage, 7, 23-29.

Hanley, J.R., \& Bakopoulou, E. Irrelevant speech, articulatory suppression and phonological similarity: a test of the phonological loop model and the feature model. Psychonomic Bulletin \& Review, in press.

Hanley, J. R., \& Broadbent, C. (1987). The effects of unattended speech on serial recall following auditory presentation. The British Journal of Psychology, 78, 287-297.

Haxby, J. V., Horwitz, B., Ungerleider, L. G., Maisog, J. M., Pietrini, P., \& Grady, C. L. (1994). The functional organization of human extrastriate cortex: a PET-rCBF study of selective attention to faces and locations. Journal of Neuroscience, 14, 6336-6353.

Haxby, J. V., Ungerleider, L. G., Horwitz, B., Rapoport, S. I., \& Grady, C. L. (1995). Hemispheric differences in neural systems for face working memory: a PET-rCBF study. Human Brain Mapping, 3, 68-82.

Hickok, G., \& Poeppel, D. (2000). Towards a functional neuroanatomy of speech perception. Trends of Cognitive Science, 4, 131-138.

Jones, C. (1993). Objects, streams, and threads of auditory attention. In A. Baddeley \& L. Weiskrantz (Ed.), Attention: Selection, awareness, and control (pp. 87-104). Oxford, England: Oxford University Press.

Jones, D. M. (1994). Disruption of memory for lip-read lists by irrelevant speech: further support for the changing state hypothesis. The Quarterly Journal of Experimental Psychology. A, 47, 143-160.

Jones, D. M., \& Macken, W. J. (1993). Irrelevant tones produce an irrelevant speech effect: implications for phonological coding in 
working memory. Journal of Experimental Psychology: Learning, Memory, \& Cognition, 19, 369-381.

Jones, D., \& Morris, N. (1992). Irrelevant speech and serial recall: implications for theories of attention and working memory. Scandinavian Journal of Psychology, 33, 212-229.

Jones, D. M., \& Macken, W. J. (1995a). Phonological similarity in the irrelevant speech effect: within- or between-stream similarity? Journal of Experimental Psychology: Learning, Memory, \& Cognition, 21, 103-133.

Jones, D. M., \& Macken, W. J. (1995b). Organizational factors in the effect of irrelevant speech: the role of spatial location and timing. Memory \& Cognition, 23, 192-200.

Jones, D. M., \& Tremblay, S. (2000). Interference in memory by process or content? A reply to Neath (2000). Psychonomic Bulletin and Review, 7, 550-558.

Jones, D. M., Miles, C., \& Page, J. (1990). Disruption of proofreading by irrelevant speech: effects of attention, arousal or memory? Applied Cognitive Psychology, 4, 89-108.

Jones, D. M., Madden, C., \& Miles, C. (1992a). Privileged access by irrelevant speech to short-term memory: the role of changing state. Quarterly Journal of Experimental Psychology. A, Human Experimental Psychology, 4, 645-669.

Jones, D. M., Madden, C., \& Miles, C. (1992b). Privileged access by irrelevant speech to short-term memory: the role of changing state. Quarterly Journal of Experimental Psychology: Human Experimental Psychology, 44a, 645-669.

Jonides, J., Smith, E. E., Koeppe, R. A., Awh, E., Minoshima, S., \& Mintun, M. A. (1993). Spatial working memory in humans as revealed by PET. Nature, 363, 623-625.

Jonides, J., Schumacher, E. H., Smith, E. E., Lauber, E. J., Awh, E., \& Minoshima, S. (1997). Verbal working memory load affects regional brain activation as measured by PET. Journal of Cognitive Neuroscience, 9, 462-475.

Jonides, J., Schumacher, E. H., Smith, E. E., Koeppe, R. A., Awh, E., \& Reuter-Lorenz, P. A. (1998). The role of parietal cortex in verbal working memory. Journal of Neuroscience, 18, 5026-5034.

Larsen, J.D., \& Baddeley, A. (in press). Disruption of verbal STM by irrelevant speech, articulatory suppression and manual tapping: do they have a common source? The Quarterly Journal of Experimental Psychology. A., in press.

Larsen, J. D., Baddeley, A., \& Andrade, J. (2000). Phonological similarity and the irrelevant speech effect: implications for models of short-term verbal memory. Memory, 8, 145-158.

Lavie, N. (1995). Perceptual load as a necessary condition for selective attention. Journal of Experimental Psychology: Human Perception and Performance, 21, 451-468.

LeCompte, D. C. (1994). Extending the irrelevant speech effect beyond serial recall. Journal of Experimental Psychology: Learning, Memory \& Cognition, 20, 1396-1408.

LeCompte, D. C. (1995). An irrelevant speech effect with repeated and continuous background speech. Psychonomic Bulletin \& Review, 2, 391-397.

LeCompte, D. C. (1996). Irrelevant speech, serial rehearsal, and temporal distinctiveness: a new approach to the irrelevant speech effect. Journal of Experimental Psychology: Learning, Memory \& Cognition, 22, $1154-1165$.

LeCompte, D. C., \& Shaibe, D. M. (1997). On the irrelevance of phonological similarity to the irrelevant speech effect. Quarterly Journal of Experimental Psychology: Human Experimental Psychology, $50 a, 100-118$

Martin-Loeches, M., Schweinberger, S. R., \& Sommer, W. (1997). The phonological loop model of working memory: an ERP study of irrelevant speech and phonological similarity effects. Memory \& Cognition, 25, 471-483.

Mazoyer, B., Tzourio, N., Frak, V., Syrota, A., Murayama, N., \& Levrier, O. et al., (1993). The cortical representation of speech. Journal of Cognitive Neuroscience, 5, 467-479.
Miles, C., Jones, D. M., \& Madden, C. A. (1991). Locus of the irrelevant speech effect in short-term memory. Journal of Experimental Psychology: Learning, Memory, \& Cognition, 17, 578-584.

Monchi, O., Petrides, M., Petre, V., Worsley, K., \& Dagher, A. (2001). Wisconsin Card Sorting revisited: distinct neural circuits participating in different stages of the task identified by event-related functional magnetic resonance imaging. Journal of Neuroscience, 21, 7733-7741.

Morris, N., \& Jones, D. M. (1990). Habituation to irrelevant speech: effects on a visual short-term memory task. Perception \& Psychophysics, 47, 291-297.

Nairne, J. S. (1990). A feature model of immediate memory. Memory \& Cognition, 18, 251-269.

Neath, I. (2000). Modeling the effects of irrelevant speech on memory. Psychonomic Bulletin and Review, 7, 403-423.

Oldfield, R. C. (1971). The assessment and analysis of handedness: the Edinburgh inventory. Neuropsychologia, 9, 97-113.

Papagno, C., \& Vallar, G. (1992). Phonological short-term memory and the learning of novel words: the effect of phonological similarity and item length. Quarterly Journal of Experimental Psychology. A, Human Experimental Psychology, 44, 47-67.

Papathanassiou, D., Etard, O., Mellet, E., Zago, L., Mazoyer, B., \& Tzourio-Mazoyer, N. (2000). A common language network for comprehension and production: a contribution to the definition of language epicenters with PET. Neuroimage, 11, 347-357.

Paulesu, E., Frith, C. D., \& Frackowiak, R. S. (1993). The neural correlates of the verbal component of working memory. Nature, 362, 342-345.

Petersson, K. M., Reis, A., Askelof, S., Castro-Caldas, A., \& Ingvar, M. (2000). Language processing modulated by literacy: a network analysis of verbal repetition in literate and illiterate subjects. Journal of Cognitive Neuroscience, 12, 364-382.

Petrides, M., Alivisatos, B., Meyer, E., \& Evans, A. (1993). Functional activation of the human frontal cortex during the performance of verbal working memory tasks. PNAS, 90, 878-882.

Price, C. J., Wise, R. J., Warburton, E. A., Moore, C. J., Howard, D., \& Patterson, K. (1996). Hearing and saying: the functional neuro-anatomy of auditory word processing. Brain, 119(Pt 3), 919-931.

Raichle, M. E. (1994). Images of the mind: studies with modern imaging techniques. Annual Review Psycholgy, 45, 333-356.

Rees, G., Frith, C. D., \& Lavie, N. (1997). Modulating irrelevant motion perception by varying attentional load in an unrelated task. Science, $278,1616-1619$.

Rees, G., Frith, C., \& Lavie, N. (2001). Processing of irrelevant visual motion during performance of an auditory attention task. Neuropsychologia, 39, 937-949.

Salame, P., \& Baddeley, A. (1982). Disruption of short-term memory by irrelevant speech: implications for the structure of working memory. Journal of Verbal Learning and Verbal Behavior, 21, 150-164.

Salame, P., \& Baddeley, A. D. (1986). Phonological factors in STM: similarity and the unattended speech effect. Bulletin of the Psychonomic Society, 24, 263-265.

Salame, P., \& Baddeley, A. (1987). Noise, unattended speech and short-term memory. Ergonomics, 30, 1185-1194.

Salame, P., \& Baddeley, A. (1989). Effects of background music on phonological short-term memory. The Quarterly Journal of Experimental Psychology. A, 44, 107-122.

Schumacher, E. H., Lauber, E., Awh, E., Jonides, J., Smith, E. E., \& Koeppe, R. A. (1996). PET evidence for an amodal verbal working memory system. Neuroimage, 3, 79-88.

Shulman, G. L., Corbetta, M., Buckner, R. L., Raichle, M. E., Fiez, J. A., \& Miezin, F. M. et al., (1997). Top-down modulation of early sensory cortex. Cerebral Cortex, 7, 193-206.

Smith, E. E., \& Jonides, J. (1997). Working memory: a view from neuroimaging. Cognitive Psychology, 33, 5-42.

Smith, E. E., \& Jonides, J. (1999). Storage and executive processes in the frontal lobes. Science, 283, 1657-1661.

Smith, E. E., \& Jonides, J. (1998). Neuroimaging analyses of human working memory. Proceedings of the National Academy of Sciences of the United States of America, 95, 12061-12068. 
Smith, E. E., Jonides, J., Koeppe, R. A., Awh, E., Schumacher, E. H., \& Minoshima, S. (1995). Spatial versus object working memory: PET investigations. Journal of Cognitive Neuroscience, 7, 337-356.

Smith, E. E., Jonides, J., \& Koeppe, R. A. (1996). Dissociating verbal and spatial working memory using PET. Cerebral Cortex, 6, 11-20.

Smith, E. E., Jonides, J., Marshuetz, C., \& Koeppe, R. A. (1998). Components of verbal working memory: evidence from neuroimaging. Proceedings of the National Academy of Sciences of the United States of America, 95, 876-882.

Surprenant, A. M., Neath, I., \& LeCompte, D. C. (1999). Irrelevant speech, phonological similarity, and presentation modality. Memory, 7, 405-420.
Talairach, J., \& Tournoux, P. (1988). Co-planar stereotaxic atlas of the human brain. New York: Thieme Medical Publishers.

Wienhard, K., Dahlbom, M., Eriksson, L., Michel, C., Bruckbauer, T., \& Pietrzyk, U. et al., (1994). The ECAT EXACT HR: performance of a new high resolution positron scanner. Journal of Computer Assisted Tomography, 18, 110-118.

Worsley, K., Marrett, S., Neelin, P., Vandal, A. C., Friston, K. J., \& Evans, A. (1996). A unified statistical approach for determining significant signals in images of cerebral activation. Human Brain Mapping, 4, $58-73$. 